\title{
Comprehensive evaluation of resistance effects of pyramiding lines with different broad-spectrum resistance genes against Magnaporthe oryzae in rice (Oryza sativa L.)
}

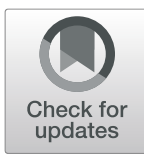

\author{
Yunyu Wu ${ }^{1,3}$, Ning Xiao ${ }^{1,3}$, Yu Chen ${ }^{4}$, Ling Y Y ${ }^{1,3}$, Cunhong Pan ${ }^{1,2}$, Yuhong Li $i^{1,3}$, Xiaoxiang Zhang ${ }^{1,3}$, \\ Niansheng Huang ${ }^{1,3}$, Hongjuan $\mathrm{ji}^{1,3}$, Zhengyuan Dai ${ }^{1,2}$, Xijun Chen ${ }^{4^{*}}$ and Aihong $\mathrm{Li}^{1,2,3^{*}}$
}

\begin{abstract}
Background: Broad-spectrum resistance gene pyramiding helps the development of varieties with broad-spectrum and durable resistance to M. oryzae. However, detailed information about how these different sources of broadspectrum resistance genes act together or what are the best combinations to achieve broad-spectrum and durable resistance is limited.

Results: Here a set of fifteen different polygene pyramiding lines (PPLs) were constructed using marker-assisted selection (MAS). Using artificial inoculation assays at seedling and heading stage, combined with natural induction identification under multiple field environments, we evaluated systematically the resistance effects of different alleles of Piz locus (Pigm, Pi40, Pi9, Pi2 and Piz) combined with Pi1, Pi33 and Pi54, respectively, and the interaction effects between different $R$ genes. The results showed that the seedling blast and panicle blast resistance levels of PPLs were significantly higher than that of monogenic lines. The main reason was that most of the gene combinations produced transgressive heterosis, and the transgressive heterosis for panicle blast resistance produced by most of PPLs was higher than that of seedling blast resistance. Different gene pyramiding with broad-spectrum $R$ gene produced different interaction effects, among them, the overlapping effect (OE) between $R$ genes could significantly improve the seedling blast resistance level of PPLs, while the panicle blast resistance of PPLs were remarkably correlated with OE and complementary effect (CE). In addition, we found that gene combinations, Pigm/Pi1, Pigm/Pi54 and Pigm/Pi33 displayed broad-spectrum resistance in artificial inoculation at seedling and heading stage, and displayed stable broad-spectrum resistance under different disease nursery. Besides, agronomic traits evaluation also showed PPLs with these three gene combinations were at par to the recurrent parent. Therefore, it would provide elite gene combination model and germplasms for rice blast resistance breeding program.
\end{abstract}

Conclusions: The development of PPLs and interaction effect analysis in this study provides valuable theoretical foundation and innovative resources for breeding broad-spectrum and durable resistant varieties.

Keywords: Rice, Blast resistance, Broad-spectrum resistance, Polygene pyramiding line

\footnotetext{
*Correspondence: xjchen@yzu.edu.cn; yzlah@126.com

${ }^{4}$ Colleges of Horticulture and Plant Protection, Yangzhou University,

Yangzhou 225009, China

'Lixiahe Agricultural Research Institute of Jiangsu Province, Yangzhou

225009, China

Full list of author information is available at the end of the article
} 


\section{Background}

Rice blast caused by hemibiotropic fungal pathogen Magnaporthe oryzae is one of the most widespread and devastating rice diseases (Khush and Jena 2009). Due to its wide distribution and ability to survive under wide range of environmental conditions, yield loss caused by the rice blast fungus vary from $10 \%$ to $30 \%$, meaning each year destroys abundant rice to feed more than 60 million people and economic losses over $\$ 70$ billion dollars (Scheuermann et al. 2012; Skamnioti and Gurr 2009). Deployment of resistant cultivars by introducing resistance $(R)$ genes into elite rice varieties were proved to be the most environmentally friendly and sustainable approach for blast control (Khush and Jena 2009). For the past decades, approximately $100 R$ genes and 350 quantitative trait loci (QTL) associated with blast resistance have been identified (Tanweer et al. 2015), of which $28 R$ genes have been cloned and functionally validated (Ashkani et al. 2016; Deng et al. 2017). However, most of these cloned and characterized $R$ genes only confer resistance to one or a few isolates of $M$. oryzae follow the model of gene-for-gene interaction (Jia et al. 2000), and their resistance tend to retain an effective level for only a short time, especially when the varieties with $R$ genes grown in large areas (Qu et al. 2006). Therefore, $R$ genes showed broad-spectrum resistance to a number of isolates or races from one or different countries seem to be more reliable and sustainable in breeding programs (Skamnioti and Gurr 2009).

Many broad-spectrum $R$ genes have been documented and validated, such as Piz (Kiyosawa 1967), Pi1 (Yu et al. 1991), Pi2 (Chen et al. 1996), Pi9 (Liu et al. 2002), Pi33 (Berruyer et al. 2003), Pi54 (Sharma et al. 2005), Pigm (Deng et al. 2006) and Pi40 (Jeung et al. 2007). Piz was originally reported in the U. S. cultivar Zenith and shown resistance to five U.S. races of blast (IH-1, IG-1, IC-17, IE-1 and IE1k) (RoyChowdhury et al. 2012). Pi2 was firstly identified in a highly resistant indica rice cultivar 5173 (Zhou et al. 2006). Extensive field evalutaions indicated that Pi2 showed resistance to 455 isolates collected from different regions of Philippines and most of the 792 isolates from 13 major rice regions of China (Chen et al. 1996). Pi9 in the isogenic line 75-1-127 was origin from Oryza minuta, a tetraploid wild species of the Oryza genus and the lines carrying Pi9 were highly resistant to 43 isolates collected from 13 countries $(\mathrm{Qu}$ et al. 2006). Genetic and mapping analysis also indicated Pigm and Pi40 showed broad-spectrum resistance to several races of $M$. oryzae (Deng et al. 2006; Jeung et al. 2007). Literature reports indicated that these five resistance genes were different $R$ gene alleles of the Piz locus located on the short arm near the centromere of rice chromosome 6 (Deng et al. 2006; Hayashi et al. 2004; Liu et al. 2002), and showed significant differences in patterns of resistance under different background (Wu et al. 2016, 2017). In addition, Pi1 was originally identified on long arm of chromosome 11 in cultivar LAC23 (Mackill and Bonman 1992) and was proved to confer resistance to most of the 792 isolates from 13 major rice regions of China (Chen et al. 2001). Pi54 gene was identified in a highly resistant cultivar Tetep and was mapped near Pi1 locus, it was furtherly conferred broad-spectrum resistance against predominant races of $M$. oryzae in India (Sharma et al. 2010). Lastly, Pi33 located on the short arm of chromosome 8 , showed resistance to $>2000$ isolates originating from 55 countries (Berruyer et al. 2003). MAS and conventional breeding together have facilitated the mentioned above broad-spectrum $R$ genes to be incorporated in elite rice varieties to improve their blast resistance and durability (Deepti et al. 2017), especially Pigm, Pi2 and $P i 9$ at Piz locus to overcome blast diseases in rice has been successfully demonstrated (Jiang et al. 2015; Luo et al. 2017). However, due to high variability and emergence of new virulent races in the $M$. oryzae population, $R$ genes such as Pi9, Pi5 and Pi3(t) may loss broad-spectrum resistance to the pathogen populations when deployed individually (Variar et al. 2009).

Broad-spectrum $R$ gene pyramiding helps the development of varieties with broad-spectrum and durable resistance to M. oryzae (Ellur et al. 2016; Gouda et al. 2013). However, which $R$ gene pyramiding patterns show broad-spectrum and stable blast resistance is still little known. The resistance effects of PPLs with different broad-spectrum resistance genes, such as Pi2/Pi1, Piz-t/ Pi54 and Pi1/Pi54 could be significantly improved as compared to the monogenic lines with single $R$ gene (Jiang et al. 2012; Khan et al. 2018; Xiao et al. 2017). However, gene pyramiding does not always mean that the resistance spectrum could be improved. For example, the resistance level of PPL ${ }^{\text {Piz5/Pita }}$ was even lower than that of monogenic lines with Piz5 (Hittalmani et al. 2000). Similarly, after pyramiding of $P i 9$ with Pi54, the resistance level of $\mathrm{PPL}^{P i 9 / P i 54}$ was also lower than that of monogenic lines with Pi9 (Xiao et al. 2017). Thus, the combination patterns of $R$ genes in rice varieties could affect the resistance level (Wu et al., 2015). Therefore, understanding the interaction effect between different broad-spectrum $R$ genes, discovering $R$ gene combinations with broad-spectrum and stable resistance is undoubtedly great significance for improvement of resistance to rice blast in breeding practice.

In previous study, the near-isogenic lines (NILs) of five resistance alleles of the Piz locus (Pigm, Pi9, Pi40, Pi2 and $P i z$ ), and Pi1, Pi33 and Pi54 from other chromosome were constructed under Yangdao 6 (YD6) genetic background (Wu et al. 2016). In the present study, we crossed these lines to produce a total of fifteen PPLs, containing all possible gene combinations within a homogeneous genetic 
background. A large number of isolates collected from different ecological regions were used for seedling blast and panicle blast identification though artificial inoculation assays, combined with the natural induction under multiple field environments, the resistance effects of fifteen PPLs with different broad-spectrum $R$ genes were evaluated, and the interaction effects between different $R$ genes were analyzed to screen the best gene combinations with broad-spectrum and stable resistance. In addition, the basic agronomic traits of PPLs were investigated to evaluate the influence with different gene combination. These results will provide valuable theoretical foundation and new resistant germplasm for breeding broad-spectrum and durable resistant varieties.

\section{Results}

Development of PPLs in the genetic background of YD6

Two set of NILs which harbored different broad-spectrum resistance genes were used for the development of PPLs in this study. The first set was composed of NILs with five alleles of Piz locus (Pigm, Pi40, Pi9, Pi2 and Piz) on chromosomes 6 with YD6 as genetic background (Wu et al. 2016). The second set consisted of three NILs with YD6 as genetic background carried the broad-spectrum resistance gene Pi1, Pi33 and Pi54, respectively. The $15 \mathrm{~F}_{1}$ combinations were developed by the way of genetic mating design of North Carollina II (NCII) using the first set of five NILs as the male parent and the second set of three NILs as female parent (Fig. 1). Then, these 20 plants from each $15 \mathrm{~F}_{1}$ combinations were screened for their heterozygosity with the help of gene specific markers and the "true" intercross. After selfed, the seeds of each combination were harvested and plant $1000 \mathrm{~F}_{2}$ populations, respectively. Foreground analysis of these populations with the gene specific markers and phenotype selection revealed that a total of 10 to 35 homozygous double gene positive plants were identified, respectively. Then, 2 to 4 homozygous $F_{3}$ lines of each gene combination with agronomic traits similar to those of YD6 were selected for detection of the back ratio of genetic background using the genotyping by sequencing (GBS) method. Lines with the highest back ratio of genetic background were selected for subsequent resistance and agronomic trait evaluation. Sequencing results showed that the back ratios of genetic background of the target PPLs were more than $98.02 \%$, ranging from $98.02 \%\left(\mathrm{PPL}^{P i 2 / P i 54}\right)$ to 98.98\% (PPL $^{\text {Pi2/Pi33) }}$ (Additional file 1: Table S1), indicated that the genetic background of all PPLs were almost fully identical to that of the recurrent parent YD6.

Transgressive heterosis improve the seedling and panicle resistance spectrum of PPLs

Eight NILs, fifteen PPLs and the recurrent parent were artificially inoculated with the collected isolates of $M$. oryzae at the seedling stage and heading stage respectively, and the results showed that there was a strong correlation between seedling blast and panicle blast resistance in NILs and PPLs, and the determination coefficient $\left(R^{2}\right)$ was 0.6659 and 0.5494 , respectively (Fig. 2 a and b). We further analyzed the resistance level between PPLs and the NILs, and found that the seedling blast and panicle blast resistance levels of PPLs were significantly higher than that of NILs after pyramiding of different $R$ genes (Fig. 2c, d). With regard to the seedling blast resistance, different gene combination produced different resistance effects, most of the fifteen gene combinations obtained transgressive heterosis $(\mathrm{TH})$ except for three gene combinations of Pi40/Pi33, Piz/Pi54 and Piz/Pi33. Despite the RF of NIL with Pigm was as high as $91.77 \%$, it produced $5.90 \%$, $3.80 \%$ and $0.64 \%$ of $\mathrm{TH}$ at the seedling stages when Pigm combined with Pi1, Pi54 and Pi33, respectively, resulting in further improvement of resistance after gene combination (Fig. 2e). Similarly, there were twelve gene combinations obtained $\mathrm{TH}$ for panicle blast resistance except for three gene combinations of Pi9/Pi1, Piz/Pi1 and Piz/Pi54 at the panicle stage. Although the RF of NIL with Pigm was $76.67 \%$, it produced $16.67 \%, 16.67 \%$ and $10.00 \%$ of TH when Pigm combined with Pi1, Pi54 and Pi33, resulting in the RF of PPL ${ }^{\text {Pigm/Pi1 }}, \mathrm{PPL}^{\text {Pigm/Pi54 }}$ and PPL ${ }^{\text {Pigm/Pi33 }}$ was as high as $93.33 \%, 93.33 \%$ and $86.67 \%$, respectively. Interestingly, the RF of NIL with Pi2 was only $33.33 \%$, but the RF PPL ${ }^{P i 2 / P i 1}$ and PPL ${ }^{P i 2 / P i 33}$ was as high as $83.33 \%$ and $70.00 \%$ after $P i 2$ combined with Pi1 and Pi33, which produced $30.00 \%$ and $36.67 \%$ of $\mathrm{TH}$, respectively (Fig. 2e). The PPLs present a broader resistant spectrum than NILs is that the PPLs' partial resistant spectrum is overlapped with the resistant spectrum of the resistant $R$ genes, PPL and NIL is of the same $\mathrm{R}$ gene that shows resistance to the same physiological isolates (Additional file 2: Figure S1). Furthermore, we also found that the $\mathrm{TH}$ for panicle blast resistance produced by most of PPLs is higher than that of seedling blast resistance. The mean value of $\mathrm{TH}$ for seedling blast resistance produced by PPLs was only $4.38 \%$, and ranged from $0.63 \%$ to $9.91 \%$. Correspondingly, the mean value of $\mathrm{TH}$ for panicle blast resistance was $16.94 \%$, and distributed between $3.34 \%$ and $36.67 \%$. Therefore, although the TH for seedling blast and panicle blast resistance was different produced by different PPLs with different broad-spectrum resistance genes combined, the broad-spectrum $R$ gene pyramiding was still effective in broadening resistance spectrum and improving the durable resistance of the target materials.

\section{Interaction effects between different broad-spectrum $R$ genes affect the resistance level of PPLs}

In order to analyze the reason that PPLs' RF is higher than NILs' RF, we classified the resistance effect of PPLs 


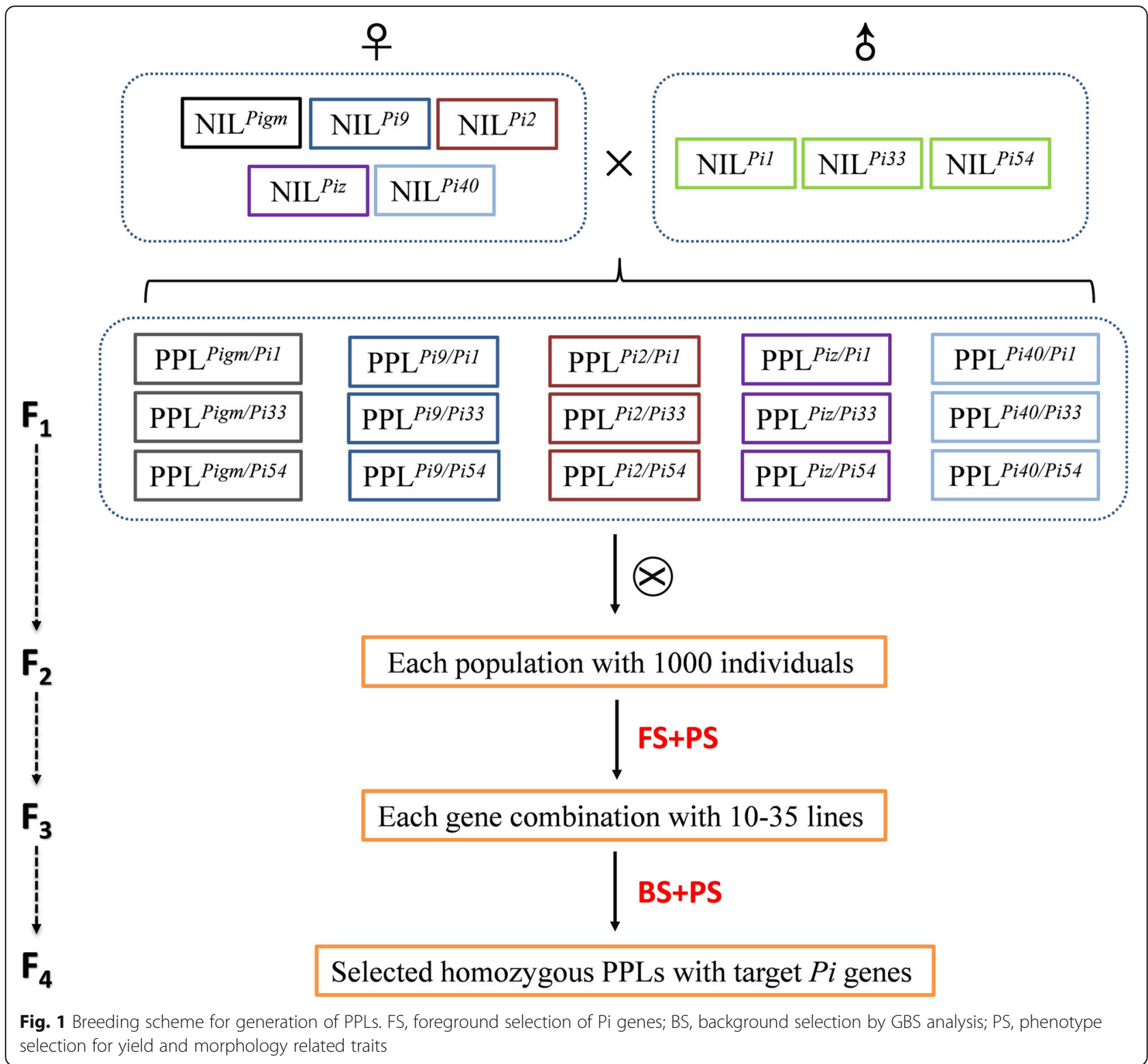

against isolates of $M$. oryzae into four interaction effects, including: (1) PPLs' partial resistant spectrum is overlapped with the resistant spectrum of both $R$ genes, which is called the overlapping effect (OE); (2) PPLs' partial resistant spectrum is overlapped with the resistant spectrum of the resistant $R$ genes, which is called the complementary effect (CE); (3) PPLs present resistance to the physiological races that are sensitivity character to NILs with $R$ gene, which is called the positive interaction effect (PIE); (4) PPLs present sensitivity to the physiological races that are resistance to NILs with $R$ gene, which is called the negative interaction effect (NIE) (Fig. 3a). Analysis the relationship of the above four effects with RF of PPLs suggested that seedling blast RF of PPLs were mainly determined by $\mathrm{OE}(\beta=1.07)$, while the panicle blast RF of PPLs were remarkably determined by $\mathrm{OE}(\beta=0.665)$ and $\mathrm{CE}(\beta=0.52)$ (Fig. 3b). Principal component analysis was conducted to ascertain which effects are the major contributing factor in the RF of PPLs. The result also showed that $\mathrm{OE}$ as a major factor affected the seedling blast resistance $\left(\mathrm{R}^{2}=65.21 \%\right)$, the $\mathrm{RF}$ of $\mathrm{PPL}^{\text {Pigm/Pi1 }}$, $\mathrm{PPL}^{\text {Pigm/Pi54 }}, \mathrm{PPL}^{\text {Pigm/Pi33 }}, \mathrm{PPL}^{\text {Pi9/Pi1 }}, \mathrm{PPL}^{\text {Pi9/Pi54 }}, \mathrm{PPL}^{\text {Pi2/Pi1 }}$, $\mathrm{PPL}^{\text {Pi2/Pi54 }}$ and $\mathrm{PPL}^{\text {Pi2/Pi33 }}$ were higher than $90 \%$ (Fig. 3c), and all of these nine PPLs had high OE, which was 74.3\%, $78.2 \%, 58.8 \%, 67.1 \%, 70.9 \%, 73.1 \%, 75.6 \%$ and $55.19 \%$, respectively (Fig. 4a). PPL ${ }^{\text {Pi40/Pi33 }}$ and PPL ${ }^{\text {Piz/Pi33 }}$ had the lowest RF and only displayed OE values of $39.24 \%$ and $15.19 \%$, respectively. Different from the seedling blast resistance, the panicle blast resistance was positively correlated with $\mathrm{OE}$ and $\mathrm{CE}\left(\mathrm{R}^{2}=66.09 \%\right)$ (Fig. 3d). The RF of 


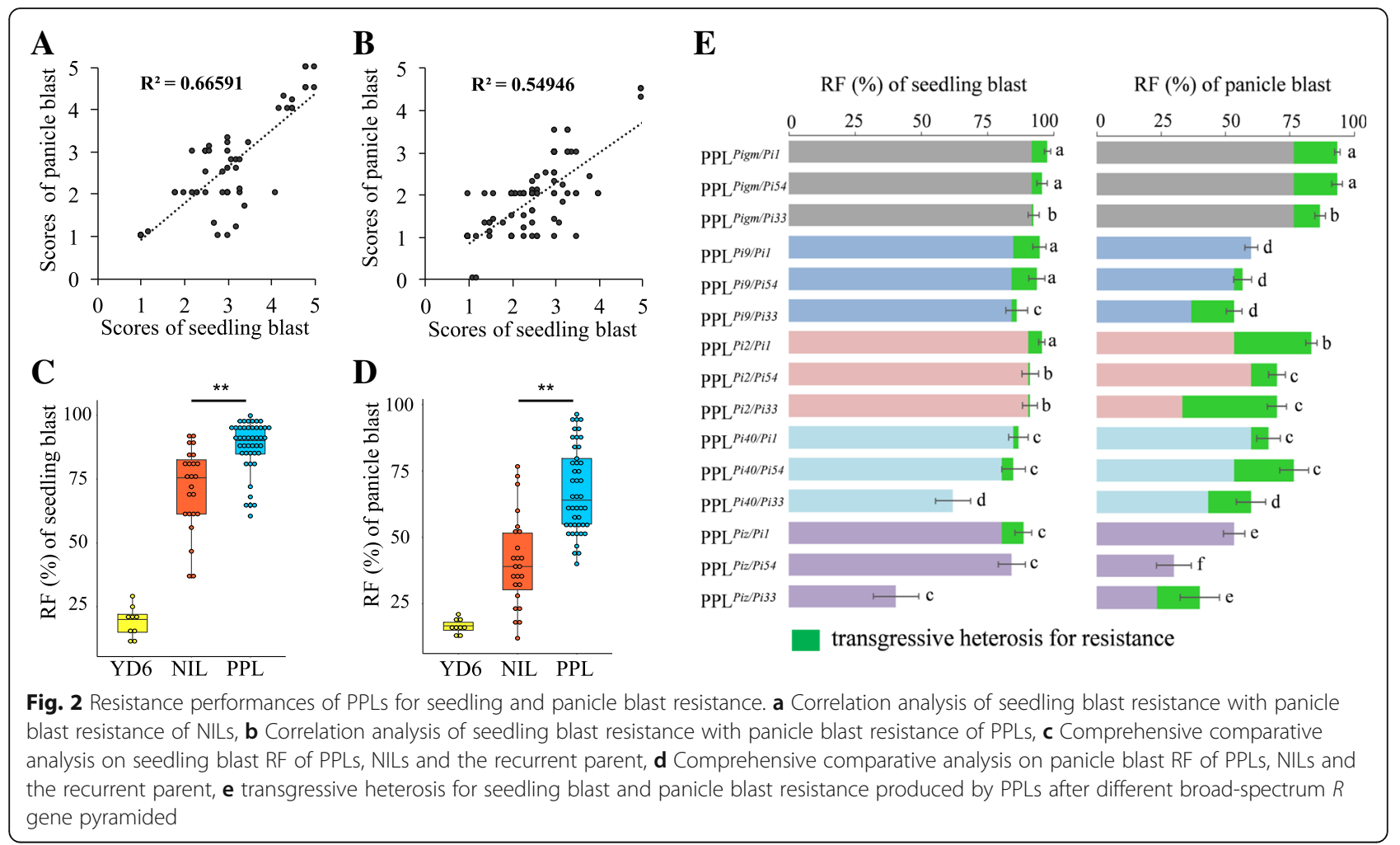

$\mathrm{PPL}^{\text {Pigm/Pi1 }}, \mathrm{PPL}^{\text {Pigm/Pi54 }}, \mathrm{PPL}^{\text {Pigm/Pi33 }}$ and $\mathrm{PPL}^{\text {Pi2/Pi1 }}$ were all higher than $80 \%$, and their corresponding OE combined with $\mathrm{CE}$ also had high values, which were $80.0 \%, 76.7 \%$, $66.7 \%$ and $53.3 \%$, respectively, while $\mathrm{PPL}^{\text {Piz/Pi54 }}$ had the lowest panicle blast RF and the value Of OE combined with CE was only $26.67 \%$. The above results suggested that gene pyramiding of different broad-spectrum $R$ gene produced different interaction effects and the interaction effect between different broad-spectrum $R$ genes affect the resistance level of PPLs. Therefore, choosing the elite gene combination is key step to breed broad-spectrum resistance varieties in breeding practices.

\section{The PPLs with Pigm and Pi2 displayed effective and stable broad-spectrum resistance in multi-location blast nurseries}

To characterize the disease resistance of PPLs under natural conditions with high blast disease pressure, field assays were performed under natural conditions in Shanghang in Zhejiang province, Jinggangshan in Jiangxi province and
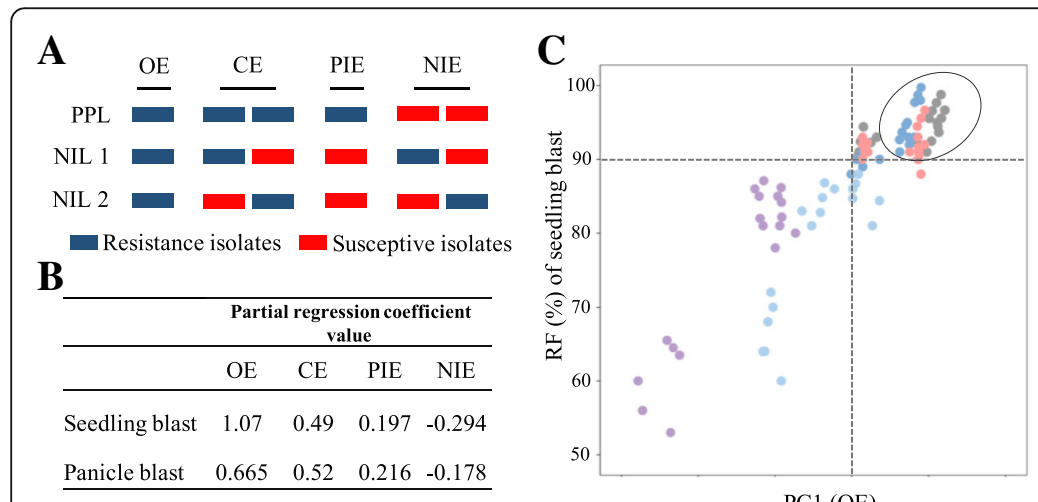

Fig. 3 Different interaction effects in PPLs and their relationship with seedling blast and panicle blast RF of PPLs. a Four interaction effects produced in PPLs, $\mathbf{b}$ Correlation between interaction effects and RF of PPLs. $\beta$ is the partial regression coefficient value of the linear regression, $\mathbf{c}$ Principal component analysis of OE with seedling blast RF of PPLS, d Principal component analysis of OE + CE with panicle blast RF of PPLs

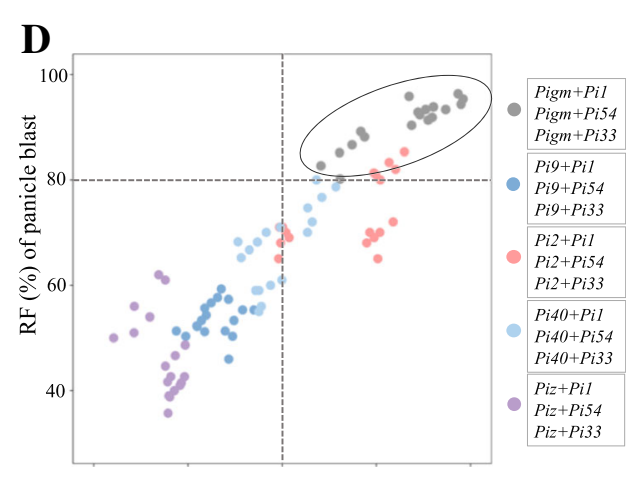

$\mathrm{PC} 1(\mathrm{OE}+\mathrm{CE})$ 
A

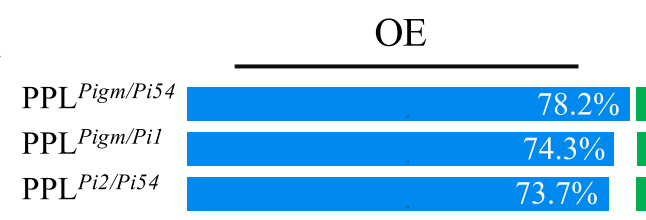

PPL ${ }^{P i 2 / P i 1}$

PPL $^{P i 9 / P i 54}$

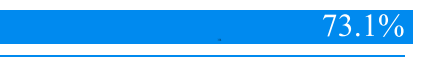

$\mathrm{PPL}^{\text {Pig/Pil }}$

PPL $^{P i 9 / P i 33}$

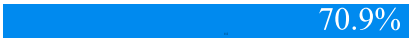

PPL ${ }^{\text {Pigm/Pi33 }}$

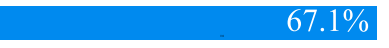

$\mathrm{PPL}^{\text {Pi2/Pi33 }}$

$\mathrm{PPL}^{\mathrm{P} i 40 / \mathrm{P} i 54}$

PPL $^{\text {Pi40/Pi1 }}$

PPL ${ }^{P i 40 / P i 33}$

PPL ${ }^{P i z / P i 1}$

$\mathrm{PPL}^{\text {Piz/Pi54 }}$

$\mathrm{PPL}^{\mathrm{Piz} / \mathrm{Pi} 3}$

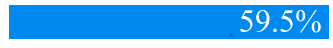

$55.8 \%$
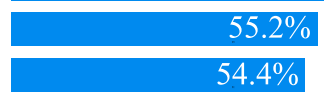

$50.7 \%$
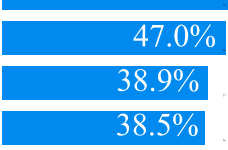

$20.2 \%$

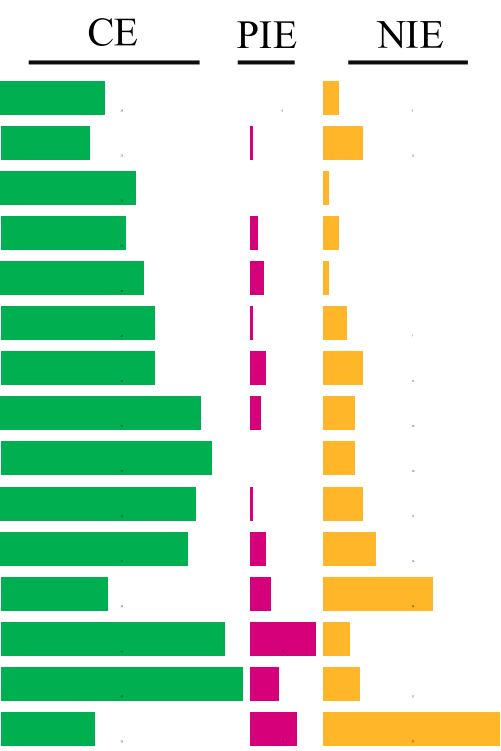

20 isolates

B

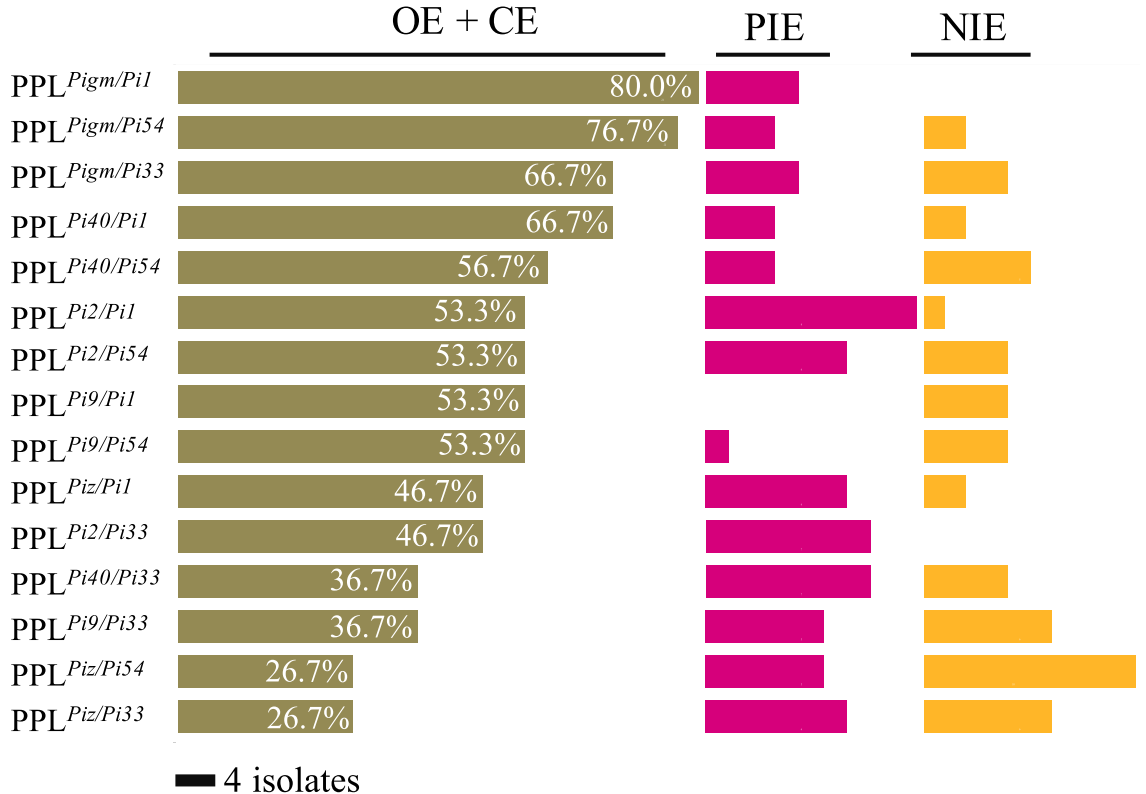

Fig. 4 Four interaction effects affect the seedling and panicle blast resistance level of PPLs. a The interaction effects affect seedling blast resistance level of PPLs, $\mathbf{b}$ The interaction effects affect panicle blast resistance level of PPLs

Huangshan in Anhui province. In the ripe stage (30 days after heading), panicle blast evaluation was represented by healthy panicle proportion $(\mathrm{HPP})$, defined as $\mathrm{HPP}=($ total panicles inoculated - diseased panicles/ total panicles inoculated) $\times 100 \%$. The recurrent parent YD6 was found to be highly susceptible at these three locations, indicated that these locations possess suitable field conditions for blast disease development and are ideal nurseries. The results showed that the natural evaluation results were consistent with the artificial inoculation identification results, and the determination coefficient $\left(R^{2}\right)$ between natural evaluation and artificial inoculation identification in Shanghang, Jinggangshan and Huangshan was 0.7223, 0.8025 and 0.7117, respectively (Fig. 5a). From Fig. $5 \mathrm{~b}$ result, we found that the $\mathrm{NIL}^{\text {Pigm }}$ and $\mathrm{NIL}^{P i 2}$ showed minimum resistance fluctuation and displayed broader resistance under Shanghang, Huangshan and Jianggangshan test sites. Moreover, $\mathrm{PPL}^{\text {Pigm/Pi1 }}, \mathrm{PPL}^{\text {Pigm/Pi54 }}, \mathrm{PPL}^{\text {Pigm/Pi33 }}, \mathrm{PPL}^{\text {Pi2/Pi1 }}, \mathrm{PPL}^{\text {Pi2/Pi54 }}$ and $\mathrm{PPL}^{P i 2 / P i 33}$ also showed minimum resistance fluctuation and displayed effective and stable broad-spectrum resistance under three test sites (Fig. 5c). Except for PPL ${ }^{P i 2 / P i 33}$, the HPP of other five PPLs were ranging from $93.05 \%$ to 


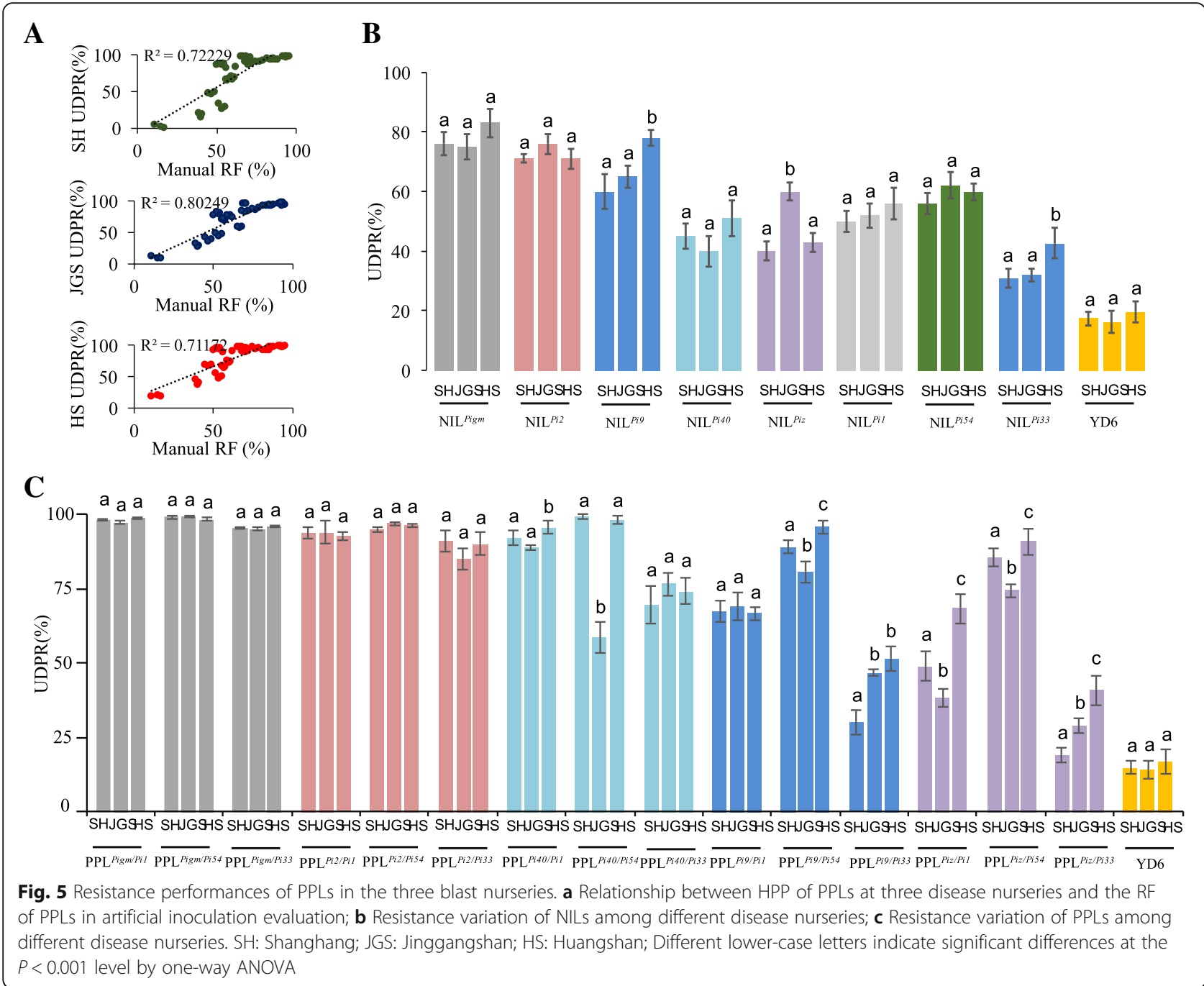

99.65\% with resistance scores of 1 to 3 . Besides, there were great differences in the panicle blast resistance of PPLs $\left(\mathrm{PPL}^{P i 40 / P i 1}, \mathrm{PPL}^{\text {Pit0/Pi54 }}, \mathrm{PPL}^{\text {Pit0/Pi33 }}, \mathrm{PPL}^{\text {Pi9/Pi1 }}, \mathrm{PPL}^{\text {Pi9/Pi54 }}\right.$, $\mathrm{PPL}^{\text {Pig/Pi33 }}, \mathrm{PPL}^{\text {Piz/Pi1 }}, \mathrm{PPL}^{\text {Piz/Pi54 }}$ and $\mathrm{PPL}^{\text {Piz/Piz3 }}$ ) at different test sites, such as the HPP of PPL ${ }^{\text {Pi40/Pi54 }}$ was $99.35 \%$ and $98.00 \%$ and displayed $R$ level with resistance scores of 1 in Shanghang and Huangshan, respectively. However, the

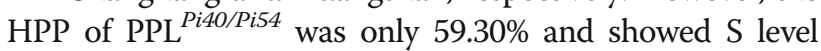
with resistance scores of 7 in Jinggangshan, indicated that the gene combination of Pi40/Pi54 showed a certain degree of specific compatibility to rice blast fungus populations in Jinggangshan (Fig. 5b, Table 1).

\section{Agronomic performances of the PPLs}

The agronomic traits of PPLs and recurrent parent YD6 were investigated and the results showed that most of the agronomic performance of PPLs, such as PH, PN, TSP, SF, GW and YPP, were similar to those of YD6, only significant variation was observed with respect to $\mathrm{PH}$, DFF, TSP and YPP among the PPL ${ }^{P i 2 / P i 1}$, $\mathrm{PPL}^{P i 2 / P i 54}$ and
$\mathrm{PPL}^{\text {Pi2/Pi33 }}$ as compared to YD6 (Table 2). In addition, we found that the yield traits of all the other PPLs were comparable to the recurrent parent, especially the YPP and the other yield component traits of $\mathrm{PPL}^{\text {Pigm/Pi1 }}$, $\mathrm{PPL}^{\text {Pigm/Pi54 }}$ and PPL ${ }^{\text {Pigm/Pi33 }}$ were at par to YD6, indicating that most of the genetic background that control elite agronomic trait of the recurrent parent were retained in the PPLs after previous agronomic trait selection and whole genome selection.

\section{Discussion}

Enhancing the host rice resistance is being considered as the best approach to handle the rice blast disease. Pyramiding of broad-spectrum $R$ genes into a rice variety has been proved to be an effective way to control rice blast (Ashkani et al. 2015; Khan et al. 2018). Ellur et al. (2016) introduced Pi2 and Pi54 into Basmati rice simultaneously, and found that the PPLs with Pi2 and Pi54 were not only effective in northern and eastern parts of India, but also in the southern parts of the country such as 
Table 1 Resistant performance of panicle blast for PPLs and the recurrent parent at three hotspot locations during the summer season in 2017

\begin{tabular}{|c|c|c|c|c|c|c|}
\hline \multirow[t]{2}{*}{ Genotypes } & \multicolumn{2}{|l|}{ Shanghang } & \multicolumn{2}{|c|}{ Jinggangshan } & \multicolumn{2}{|l|}{ Huangshan } \\
\hline & HPP (\%) & $\begin{array}{l}\text { Disease } \\
\text { score }\end{array}$ & HPP (\%) & $\begin{array}{l}\text { Disease } \\
\text { score }\end{array}$ & HPP (\%) & $\begin{array}{l}\text { Disease } \\
\text { score }\end{array}$ \\
\hline PPLPigm/Pi1PPLPigm/Pi1 & $98.85 \pm 1.05$ & 1 & $96.00 \pm 1.05$ & 1 & $98.90 \pm 0.70$ & 1 \\
\hline PPLPigm/Pi54PPLPigm/Pi54 & $99.65 \pm 0.35$ & 1 & $99.25 \pm 0.25$ & 1 & $98.20 \pm 1.05$ & 1 \\
\hline PPLPigm/Pi33PPLPigm/Pi33 & $95.20 \pm 1.28$ & 1 & $95.75 \pm 2.72$ & 1 & $98.15 \pm 0.61$ & 1 \\
\hline PPLPi2/Pi1PPLPi2/Pi1 & $95.90 \pm 1.05$ & 1 & $94.40 \pm 1.58$ & 3 & $93.05 \pm 3.07$ & 3 \\
\hline PPLPi2/Pi54PPLPi2/Pi54 & $96.70 \pm 0.32$ & 1 & $96.70 \pm 3.69$ & 1 & $96.35 \pm 2.55$ & 1 \\
\hline PPLPi2/Pi33PPLPi2/Pi33 & $89.45 \pm 1.35$ & 5 & $85.05 \pm 4.65$ & 5 & $90.30 \pm 3.68$ & 3 \\
\hline PPLPi40/Pi1PPLPi40/Pi1 & $92.95 \pm 1.47$ & 3 & $89.90 \pm 2.81$ & 5 & $95.45 \pm 2.02$ & 1 \\
\hline PPLPi40/Pi54PPLPi40/Pi54 & $99.35 \pm 0.45$ & 1 & $59.30 \pm 5.09$ & 7 & $98.00 \pm 1.81$ & 1 \\
\hline PPLPi40/Pi33PPLPi40/Pi33 & $70.00 \pm 4.25$ & 7 & $77.10 \pm 6.32$ & 5 & $74.05 \pm 2.73$ & 7 \\
\hline PPLPi9/Pi1PPLPi9/Pi1 & $69.05 \pm 6.41$ & 7 & $68.80 \pm 4.04$ & 7 & $66.75 \pm 6.43$ & 7 \\
\hline PPLPi9/Pi54PPLPi9/Pi54 & $89.05 \pm 3.95$ & 5 & $81.00 \pm 5.79$ & 5 & $95.85 \pm 0.79$ & 1 \\
\hline PPLPi9/Pi33PPLPi9/Pi33 & $29.95 \pm 3.95$ & 9 & $47.85 \pm 6.06$ & 9 & $51.30 \pm 15.63$ & 7 \\
\hline PPLPiz/Pi1PPLPiz/Pi1 & $50.35 \pm 7.11$ & 7 & $38.85 \pm 4.63$ & 9 & $68.50 \pm 2.98$ & 7 \\
\hline PPLPiz/Pi54 & $85.35 \pm 4.83$ & 5 & $73.70 \pm 3.38$ & 7 & $90.65 \pm 2.72$ & 3 \\
\hline PPLPiz/Pi33 & $19.70 \pm 5.45$ & 9 & $28.95 \pm 4.52$ & 9 & $40.30 \pm 5.66$ & 9 \\
\hline YD6 & $3.25 \pm 1.05$ & 9 & $8.70 \pm 1.85$ & 9 & $20.55 \pm 4.65$ & 9 \\
\hline
\end{tabular}

Pattambi, Kerala, and Gudalur, Tamil Nadu. Similarly, the rice variety Jefferson with the gene combination of Pik/Piz has remained resistant since its first application in 1997 (Fjellstrom et al. 2004; McClung et al. 1997). In this study, we constructed a total of 15 PPLs using the NILs with different $R$ genes (Pigm, Pi2, Pi9, Pi40 and Piz) from Piz locus as core parents and pyramided with Pi1, Pi33 and Pi54, respectively. Seedling blast evaluation results showed that most of PPLs could produce $\mathrm{TH}$, which resulting in the RF of PPLs was significantly higher than that of NILs. The seedling blast resistant frequency of $\mathrm{PPL}^{\text {Pigm/Pi1 }}$, $\mathrm{PPL}^{\text {Pigm/Pi54 }}, \mathrm{PPL}^{\text {Pigm/Pi33 }}, \mathrm{PPL}^{\text {Pig/Pi1 }}, \mathrm{PPL}^{\text {Pig/Pi54 }}, \mathrm{PPL}^{\text {Pi2/Pi1 }}$,

Table 2 Agronomic performance of PPLs and the recurrent parent during the summer season in 2017

\begin{tabular}{|c|c|c|c|c|c|c|c|}
\hline Genotypes & $\mathrm{PH}(\mathrm{cm})$ & DFF (days) & PN & TSP & GW (g) & $\mathrm{SF}(\%)$ & YPP (g) \\
\hline PPLPigm/Pi1 & $116.25 \pm 2.36$ & $101.50 \pm 0.50$ & $7.80 \pm 0.99$ & $174.40 \pm 10.64$ & $30.60 \pm 0.50$ & $93.05 \pm 1.12$ & $35.15 \pm 0.62$ \\
\hline PPLPigm/Pi54 & $117.04 \pm 4.60$ & $99.50 \pm 1.00$ & $8.45 \pm 0.62$ & $174.25 \pm 4.84$ & $30.85 \pm 0.87$ & $91.65 \pm 0.62$ & $35.40 \pm 1.74$ \\
\hline PPLPigm/Pi33 & $111.35 \pm 5.09$ & $101.00 \pm 0.50$ & $8.50 \pm 0.75$ & $174.25 \pm 10.06$ & $29.95 \pm 0.37$ & $93.20 \pm 1.74$ & $34.95 \pm 0.63$ \\
\hline PPLPi40/Pi1 & $116.05 \pm 3.61$ & $100.50 \pm 1.24$ & $8.10 \pm 0.25$ & $176.50 \pm 10.18$ & $29.85 \pm 0.62$ & $91.75 \pm 1.12$ & $33.85 \pm 0.62$ \\
\hline PPLPi40/Pi54 & $114.95 \pm 3.35$ & $100.50 \pm 1.00$ & $8.05 \pm 0.37$ & $173.30 \pm 6.21$ & $29.95 \pm 0.62$ & $93.05 \pm 1.12$ & $34.85 \pm 0.87$ \\
\hline PPLPi40/Pi33 & $111.10 \pm 5.96$ & $100.50 \pm 0.50$ & $8.50 \pm 0.50$ & $171.45 \pm 5.09$ & $29.70 \pm 0.25$ & $91.95 \pm 1.61$ & $35.80 \pm 0.74$ \\
\hline PPLPi9/Pi1 & $116.00 \pm 1.99$ & $99.50 \pm 1.24$ & $7.75 \pm 0.37$ & $174.90 \pm 20.62$ & $29.05 \pm 0.62$ & $91.55 \pm 2.36$ & $34.80 \pm 1.49$ \\
\hline PPLPi9/Pi54 & $117.40 \pm 1.99$ & $99.00 \pm 2.48$ & $8.20 \pm 0.99$ & $172.80 \pm 12.67$ & $30.25 \pm 0.87$ & $92.25 \pm 1.12$ & $34.90 \pm 0.50$ \\
\hline PPLPi9/Pi33 & $115.45 \pm 1.86$ & $99.00 \pm 1.00$ & $7.70 \pm 0.99$ & $173.25 \pm 7.331$ & $30.15 \pm 1.37$ & $92.95 \pm 1.12$ & $35.35 \pm 1.37$ \\
\hline PPLPi2/Pi1 & $115.10 \pm 4.22$ & $94.50 \pm 1.50^{* *}$ & $8.50 \pm 0.99$ & $150.20 \pm 5.96^{* *}$ & $30.00 \pm 0.75$ & $93.50 \pm 0.75$ & $32.85 \pm 0.87^{* *}$ \\
\hline PPLPi2/Pi54 & $113.20 \pm 1.49$ & $96.00 \pm 1.50^{*}$ & $8.35 \pm 0.37$ & $143.40 \pm 5.47^{* *}$ & $29.05 \pm 0.87$ & $92.60 \pm 2.24$ & $32.95 \pm 0.37^{* *}$ \\
\hline PPLPi2/Pi33 & $106.25 \pm 2.36^{* *}$ & $95.00 \pm 1.50^{* *}$ & $7.75 \pm 0.37$ & $147.35 \pm 6.83^{* *}$ & $29.00 \pm 0.99$ & $91.20 \pm 1.49$ & $33.90 \pm 0.74^{*}$ \\
\hline PPLPiz/Pi1 & $114.85 \pm 0.62$ & $101.50 \pm 0.50$ & $8.05 \pm 0.62$ & $173.65 \pm 3.11$ & $30.00 \pm 0.99$ & $93.20 \pm 1.49$ & $34.40 \pm 0.75$ \\
\hline PPLPiz/Pi54 & $115.00 \pm 1.99$ & $98.50 \pm 1.00$ & $8.60 \pm 0.75$ & $177.75 \pm 9.81$ & $29.95 \pm 1.12$ & $92.30 \pm 2.73$ & $34.10 \pm 0.99$ \\
\hline PPLPiz/Pi33 & $113.20 \pm 2.24$ & $99.50 \pm 0.50$ & $7.90 \pm 0.99$ & $176.35 \pm 5.34$ & $29.85 \pm 1.12$ & $92.25 \pm 3.11$ & $35.65 \pm 1.37$ \\
\hline YD6 & $114.95 \pm 0.62$ & $99.50 \pm 0.50$ & $8.05 \pm 0.62$ & $175.45 \pm 7.57$ & $29.85 \pm 0.62$ & $93.10 \pm 0.75$ & $35.10 \pm 0.25$ \\
\hline
\end{tabular}

*: significant differences at $P<0.05 ;{ }^{* *}$ : significant differences at $P<0.001$ 
$\mathrm{PPL}^{\text {Pi2/Pi54 }}$ and PPL ${ }^{\text {Pi2/Pi33 }}$ were higher than $90 \%$, and their $\mathrm{TH}$ was ranging from $0.63 \%$ to $9.91 \%$. Similarly, for panicle blast resistance, the RF of $\mathrm{PPL}^{\text {Pigm/Pi1 }}$, $\mathrm{PPL}^{\text {Pigm/Pi54, }}$ $\mathrm{PPL}^{\text {Pigm/Pi33 }}$ and PPL ${ }^{P i 2 / P i 1}$ were higher than $80 \%$, and their $\mathrm{TH}$ was ranging from $10.00 \%$ to $30.00 \%$. These results suggested that $\mathrm{TH}$ play more important role on enhancing panicle blast resistance than seedling blast resistance. Furtherly, under natural identification at multi-location disease nursery, the $\mathrm{PPL}^{\text {Pigm/Pi1 }}$, $\mathrm{PPL}^{\text {Pigm/Pi54 }}$, $\mathrm{PPL}^{\text {Pigm/Piz3 }}$, $\mathrm{PPL}^{P i 2 / P i 1}, \mathrm{PPL}^{P i 2 / P i 54}$ and PPL ${ }^{P i 2 / P i 33}$ presented minimum resistance fluctuation character, and their agronomic traits were at par with the recurrent parent. Therefore, it indicated that selecting effective $R$ genes and pyramiding them in an optimal combination pattern is the vital step in resistance breeding programs. The gene combinations Pigm/ Pi1, Pigm/Pi54 and Pigm/Pi33 exhibited the best resistance level both at seedling and heading stage, which could provide useful genes resource for blast resistance breeding practice. However, Pi2/Pi1 was excellent in resistance to rice blast after introduced into the background of Yangdao 6 , but there may be some genes that control undesirable agronomic traits around the target gene combination, causing so-called linkage drag, which makes it difficult to be applied directly in breeding practice.

Different $R$ genes often confer resistance to different isolates, races or biotypes. Combining their resistance broadens the number of races or isolates and increases resistance spectrum (Feechan et al. 2015). In this study, we found that the OE of PPLs is one of the most important factors to improve seedling blast resistance level, and all of the gene combinations with effective resistance had a relatively high OE. For example, the gene combination Pigm/ Pi1, the OE between Pigm and Pi1 was $77.22 \%$ after pyramided and caused the RF of PPL ${ }^{\text {Pigm/Pi1 }}$ to be as high as 97.67\%, while PPL ${ }^{\text {Piz/Pi33 }}$ with $15.19 \%$ of OE showed the lowest seedling blast RF (37.25\%). In addition, the CE of PPLs is another important component factor of its broad-pectrum resistance. The larger the $\mathrm{CE}$ value, the more the number of isolates of $M$. oryzae collaboratively resisted by the two pyramided $R$ genes. Here, we found that the panicle blast resistance was not only related to $\mathrm{OE}$ but also related with $\mathrm{CE}$. The $\mathrm{OE}$ and $\mathrm{CE}$ values could be observed in various degrees to broaden the panicle blast resistance spectrum of PPLs compared with that of monogenic lines. The gene combination Pigm/Pi1 with $80.22 \%$ of OE and CE present $94.33 \%$ of panicle blast RF, while PPL ${ }^{P i z / P i 33}$ with $20.01 \%$ of OE and CE showed the lowest seedling blast RF (39.65\%). Therefore, choosing $R$ gene combination with higher $C E$ value will be useful for improving panicle blast resistance.

Except for $\mathrm{OE}$ and $\mathrm{CE}$ could improve the resistant spectrum in PPLs, the PIE also could enhance the seedling blast and panicle blast resistance spectrum of PPLs. Although the panicle blast RF of $\mathrm{NIL}^{P i 2}$ and $\mathrm{NIL}^{P i 1}$ were
$33.33 \%$ and $53.33 \%$, respectively, the PPL ${ }^{P i 2 / P i 1}$ with $30 \%$ of PIE value presented $83.33 \%$ of panicle blast RF which was higher than that of its parental lines. However, not all gene combinations produce PIE after gene pyramided, some $R$ genes combination could also produce NIE on blast resistance (Chen et al. 2018). Such as $\mathrm{PPL}^{\text {Piz/Pi54 }}$ produced $33.33 \%$ of NIE value, which resulted in the panicle blast RF of PPL ${ }^{\text {Piz/Pis4 }}$ was lower than that of NILs with Pi54. Similar result was also reported by Hittalmani et al. (2000), the resistance level of PPLs ${ }^{\text {Piz5/Pita }}$ was lower than that of the monogenic lines with Piz5. Although the interaction effect between combined $R$ genes is extremely complex (Chaipanya et al. 2017 and Divya et al. 2014) and the mechanism of NIE produced is still unknown. However, pyramiding broad-spectrum $R$ genes, each recognizing a unique set of rice blast fungus population into a single cultivar, is still promising and effective (Ashkani et al. 2015; Pilet-Nayel et al. 2017). Nevertheless, the approaches need careful characterization of the resistance spectrum of the target $R$ genes to be used and combining them in an effective pyramiding way against the target pathogen population for crop protection.

\section{Methods}

\section{Plant materials and pathogens}

The recurrent parent indica cv. Yangdao 6 (YD6) bred by Lixiahe Agricultural Research Institute of Jiangsu Province, China, and was the two-line restorer line with the largest application area in China. At the same time, as the representative of Chinese indica rice, YD6 was the first one selected for genome sequencing research (Yu et al. 2002). The eight near-isogenic lines (NILs) with broad-spectrum $R$ resistance genes (Pigm, Pi40, Pi2, Pi9, Piz, Pi1, Pi54 and Pi33) were constructed with YD6 as genetic background.

A set of seven Chinese differential rice cultivars, Tetep, Zhenglong 13, Sifeng 43, Dongnong 363, Kanto 51, Hejiang 18, and Lijangxintuanheigu (LTH) were used to study pathogenicity and subgroups of isolates of $M$. ory$z a e$ at the seedling stage. A total of 158 isolates were collected and obtained from the diseased panicles from different parts of the infected fields in Hainan $(\mathrm{HN})$, Guangdong, Guangxi, Hunan, Hubei, Jiangsu, Zhejiang, Anhui, Jiangxi and Sichuan provinces in 2010-2016 (Additional file 3: Table S2). Single spore isolation, strain cultivation, and inoculum preparation were conducted following the procedure reported by Puri et al. (2009).

\section{Molecular marker assay} DNA isolation and PCR conditions

Three-weeks-old rice leaves were frozen in liquid nitrogen and stored at $-80^{\circ} \mathrm{C}$ until DNA extraction. Genomic DNA was extracted using the rapid extraction 
method of TPS (Lu and Zheng 1992), PCR amplification was carried out in a $20 \mu \mathrm{L}$ reaction mixture containing $2.0 \mu \mathrm{L} \mathrm{MgCl}_{2}(25 \mathrm{mmol} \mathrm{L}-1), 2.0 \mu \mathrm{L} 10 \times \mathrm{PCR}$ buffer, $1.5 \mu \mathrm{l}$ of each primer $(10 \mu \mathrm{mol} \mathrm{L}-1), 0.4 \mu \mathrm{L}$ dNTP $(10$ mmol L-1), 50 ng DNA template, $0.2 \mu \mathrm{L}$ Taq polymerase enzyme $(5 \mathrm{U} \mu \mathrm{L}-1)$ and $11.9 \mu \mathrm{L} \mathrm{ddH}_{2} \mathrm{O}$. The PCR program were conducted following the standard protocol (Chen et al. 1997), included pre-denaturation for $5 \mathrm{~min}$ at $94{ }^{\circ} \mathrm{C}$, followed by 35 cycles of $45 \mathrm{~s}$ at $94{ }^{\circ} \mathrm{C} 45 \mathrm{~s}$ at the annealing temperature indicated in Additional file 4: Table S3, $1 \mathrm{~min}$ at $72^{\circ} \mathrm{C}$, and a final extension $72{ }^{\circ} \mathrm{C}$ for $10 \mathrm{~min}$. The amplification products were visualized on $8 \%$ denaturing polyacrylamide gel or $4 \%$ agarose gel based on their relative fragment size.

\section{Foreground selection by molecular markers}

The plants were analyzed to confirm the presence of target genes using gene based/linked markers. Foreground selection for the gene Pi54 was conducted using the gene-based markers PI54-1. The selection for the genes Pigm, Pi9, Pi40, Pi2, Piz, Pi1, and Pi33 was carried out using specific gene-linked markers ZJ58.7, RM3330, ZJ58.7, AP22, AP5413, RM224 and RM72, respectively, as mentioned in the Additional file 4: Table S3.

\section{GBS background analysis}

Genomic DNA was extracted from $100 \mathrm{mg}$ of leaf tissue using DNAsecure Plant kit reagents following the manufacturer's protocol (Qiagen, USA). The quality of extracted genomic DNA was measured using BioPhotometer plus (Eppendorf, Germany). Genomic DNA was digested with restriction enzymes BamHI and MspI and sequencing libraries were prepared by ligating the digested DNA to unique nucleotide adapters (barcodes) followed by standard PCR. Sequencing was performed using Illumina HiSeq2000 Sequencer (Illumina, USA) (Poland et al. 2012). The raw Illumina DNA sequence data (FASTQ file) were processed through the GBS analysis pipeline in TASSEL v3.0 software (Bradbury et al. 2007). The raw reads were sorted according to indices, and the high-quality SNPs between parents were called by alignment with Nipponbare reference genome MSU release 7 (Kawahara et al. 2013) using BWA package (Lai et al. 2010; Li and Durbin 2009) and Genome Analysis Toolkit (GATK) (McKenna et al. 2010).

\section{Evaluation for blast resistance}

\section{Evaluation for blast resistance by artificial inoculation}

Eight NILs, fifteen PPLs and seven Chinese differential rice cultivars were screened for blast resistance under artificial conditions using a set of $158 \mathrm{M}$. oryzae isolates. Ten plants of each tested materials were grown in a plastic tray filled with sieved garden soil in greenhouse maintained at 27 to $30^{\circ} \mathrm{C}$ till three leaf emergences. Three replicates of all tested materials were included in the inoculations with the recurrent parent YD6 and the standard susceptible check LTH as the susceptible control. Three-week old rice seedlings were inoculated with $40 \mathrm{~mL}$ of an $M$. oryzae conidial suspension $\left(5 \times 10^{4}\right.$ conidia $/ \mathrm{mL}$ ) with $0.02 \%$ Tween 20 using a hand atomizer $(100 \mathrm{kPa})$ connected to an air compressor. Inoculated plants were incubated for $24 \mathrm{~h}$ in the dark in growth chambers maintained at $26^{\circ} \mathrm{C}$. Plants were transferred to the greenhouse post-inoculation under a 12-h light/12-h dark photocycle at $90 \%$ relative humidity by intermittent spraying with water. Blast disease score was recorded after seven days according to the standard procedures (Mackill and Bonman 1992), where lines with scores of 0 to 2 were considered resistant (R) and 3 to 5 were considered to be susceptible (S). The blast resistance of each NIL and PPL were identified by three replications.

The NILs, PPLs and the recurrent parent YD6 were screened resistance to panicle blast under natural conditions. A set of 30 isolates were selected from the set of 158 blast isolates for panicle blast resistance screen assays. Selection criteria were based on the virulence patterns in seven Chinese differential rice cultivars as described by Wu et al. (2016). 120 plants of each experimental material were transplanted in the paddy field. Each plot contains 10 rows and 12 plants per row with row spacing $13.3 \mathrm{~cm} \times$ $25 \mathrm{~cm}$. A completely randomized block design (RCBD) was used with three replications. Individual rice tillers were inoculated at the booting stage (the beginning of panicle initiation), by injecting $1 \mathrm{~mL}$ of an $M$. oryzae conidial suspension $\left(5 \times 10^{4}\right.$ conidia $\left./ \mathrm{mL}\right)$ into the panicle of each plant between the second and ninth rows. A total of 10 rice tillers were inoculated with each $M$. oryzae isolate. In ripe stage, the panicle blast evaluation was based on incidence rates of panicle blast symptoms and the standard reference was described by Puri (2009).

\section{Multi-location disease resistance evaluations in the blast nurseries}

The NILs and PPLs were screened for their reaction to blast under Uniform Blast Nursery (UBN) at three hot spot locations viz., Shanghang in Zhengjiang province, Jinggangshan in Jiangxi province and Huangshan in Anhui province, where possess suitable field conditions for blast disease development. Each plot had five rows and 12 plants per row with row spacing $13.3 \mathrm{~cm} \times 25 \mathrm{~cm}$, and a completely randomized block design was used with three replications. The susceptible checks were planted as a spreader in 2 rows at both sides of each block to maximize the disease incision. The water layer of field was about 10 $\mathrm{cm}$ and no fungicide was used. The disease score was recorded on the $0-5$ standard evaluation scale of IRRI (2002) with slightly modified as follows: lines with 0 score were considered as highly resistant (HR) and there were no diseased plant in the plot, 1 score was resistant $(\mathrm{R})$ and 
the health panicle proportion (HPP) in the plot was higher than $95.0 \%, 2$ was moderately resistant (MR) and the HPP in the plot was ranging from $90.1 \%$ to $95.0 \%, 3$ was moderately susceptible (MS) and the HPP in the plot was ranging from $75.1 \%$ to $90 \%$, 4 was susceptible (S) and the HPP in the plot was ranging from $50.1 \%$ to $75 \%$, where 5 were highly susceptible (HS) and the HPP in the plot was ranging from $0 \%$ to $50 \%$.

\section{Evaluation of PPLs for agronomic performance}

Evaluation of agronomic traits under natural field condition was conducted in the field at Lixiahe Agricultural Research Institute of Jiangsu Province, China (32 $38^{\prime} \mathrm{N}$ $119^{\circ} 43^{\prime}$ E). Performance of the PPLs and recurrent parent YD6 were evaluated during the summer of 2017. Each line was planted in a Plot of seven rows with 12 plants per row as described above, and a RCBD with two replications. Normal water and fertilizer management, disease and pest control were conducted. Five plants in the middle of each plot were taken randomly for measurements of days to $50 \%$ flowering (DFF), plant height $(\mathrm{PH})$, panicle number per plant $(\mathrm{PN})$, total spikelets per plant (TSP), spikelet fertility (SF), 1000 grain weight $(\mathrm{GW})$, and yield per plant (YPP), according to the standard evaluation system for rice (IRRI 2002).

\section{Data analysis}

The seedling blast and panicle blast resistance was represented by resistance frequency (RF), defined as $\mathrm{RF}=$ (number of incompatible $M$. oryzae isolates/total number of $M$. oryzae isolates inoculated $) \times 100 \%(\mathrm{Wu}$ et al. 2016). The transgressive heterosis number is calculated by using this formula: Transgressive heterosis $(\mathrm{TH})=\mathrm{RF}^{\mathrm{PPL}}-\mathrm{RF}^{\mathrm{NIL}} \cdot \mathrm{RF}^{\mathrm{PPL}}$ refers to the resistance frequency of PPL; $\mathrm{RF}^{\mathrm{NIL}}$ represents the resistance frequency of the NIL with the highest resistance frequency. The relationship between different interaction effect and RF was analyzed using a multiple stepwise regression model, which is an available option in Matlab (V.7.0) software (Xu et al. 2012). The interaction effects that were significantly correlated with $\mathrm{RF}$ were subjected to clustering by principal component analysis (PCA) in SPSS (V.21) software.

\section{Additional files}

Additional file 1: Table S1. Information of insert fragments from donor to receptor for each of the PPLs. (XLSX $11 \mathrm{~kb}$ )

Additional file 2: Figure S1. Comparing of resistant spectrum between PPLs and NILs. A Seedling blast stage; B Panicle blast stage. The number in this picture is total amount of blast isolate resistant to PPLs or NILs. (PDF $70 \mathrm{~kb}$ )

Additional file 3: Table S2. Information of blast populations for pathogenicity assays. (XLSX 19 kb)
Additional file 4: Table S3. Detail information of molecular markers tightly linked to different resistant genes. (DOCX 16 kb)

Acknowledgements

Not applicable.

Funding

This work was supported by the National Key R\&D Program of China (2017YFD0100304, 2017YFD0100402), the Natural Science Foundation of Jiangsu Province, China (BK20160447), the Project of Breeding of Key New Varieties in Jiangsu Province (PZCZ201702), the Jiangsu Province 333 Project (BRA2016145), the Molecular Breeding Technology Construction of Public Service Platform, Yangzhou City (YZ2017170), Yangzhou Science and Technology Plan (Modern Agriculture, YZ2018048), Rice Industry Technology System of Yangzhou Comprehensive Experimental Station, Yangzhou, Jiangsu Province, China (CARS-01-60).

Availability of data and materials

Not applicable.

\section{Authors' contributions}

$A L$ and $X C$ participated in the study conception and design. YC, LY, CP and $Y L$ contributed to DNA extraction and molecular marker identification. $X Z$, $\mathrm{NH}, \mathrm{HJ}$ and $\mathrm{ZD}$ contributed to data analysis. YW and NX wrote the manuscript. All authors approved the final version of the manuscript.

\section{Authors' information}

Not applicable.

Ethics approval and consent to participate

Not applicable.

\section{Consent for publication}

Not applicable.

\section{Competing interests}

The authors declare that they have no competing interests.

\section{Publisher's Note}

Springer Nature remains neutral with regard to jurisdictional claims in published maps and institutional affiliations.

\section{Author details}

'Lixiahe Agricultural Research Institute of Jiangsu Province, Yangzhou 225009, China. ${ }^{2}$ Jiangsu Collaborative Innovation Center for Modern Crop Production, Nanjing 210095, China. ${ }^{3}$ Jiangsu Key Laboratory of Crop Genomics and Molecular Breeding, Yangzhou University, Yangzhou 225009 China. ${ }^{4}$ Colleges of Horticulture and Plant Protection, Yangzhou University, Yangzhou 225009, China.

Received: 10 September 2018 Accepted: 17 January 2019

Published online: 01 March 2019

\section{References}

Ashkani S, Rafii M, Shabanimofrad M, Ghasemzadeh A, Ravanfar SA, Latif M (2016) Molecular progress on the mapping and cloning of functional genes for blast disease in rice (Oryza sativa L.): current status and future considerations. Crit Rev Biotechnol 36:353-367

Ashkani S, Rafii MY, Shabanimofrad M, Miah G, Sahebi M, Azizi P, Tanweer FA, Akhtar MS, Nasehi A (2015) Molecular breeding strategy and challenges towards improvement of blast disease resistance in rice crop. Front Plant Sci 6:886 Berruyer R, Adreit H, Milazzo J, Gaillard S, Berger A, Dioh W, Lebrun MH, Tharreau D (2003) Identification and fine mapping of Pi33, the rice resistance gene corresponding to the Magnaporthe grisea avirulence gene ACE1. Theor Appl Genet 107:1139-1147

Bradbury PJ, Zhang Z, Kroon DE, Casstevens TM, Ramdoss Y, Buckler ES (2007) TASSEL: software for association mapping of complex traits in diverse samples. Bioinformatics 23:2633-2635

Chaipanya C, Telebanco-Yanoria MJ, Quime B, Longya A, Korinsak S, Toojinda T, Vanavichit A, Jantasuriyarat C, Zhou B (2017) Dissection of broad-spectrum 
resistance of the Thai rice variety Jao Hom Nin conferred by two resistance genes against rice blast. Rice (N Y) 10:18

Chen D, Zeigler R, Ahn S, Nelson R (1996) Phenotypic characterization of the rice blast resistance gene $\mathrm{Pi}-2(\mathrm{t})$. Plant Dis 80:52-56

Chen H, Chen B, Zhang D, Xie Y, Zhang Q (2001) Pathotypes of Pyricularia grisea in rice fields of central and southern China. Plant Dis 85:843-850

Chen X, Jia Y, Jia MH, Pinson S, Wang X, Wu BM (2018) Functional Interactions between major rice blast resistance genes, $P i-t a$ and $P i-b$, and minor blast resistance QTL. Phytopathology 108(9):1095-1103.

Chen X, Temnykh S, Xu Y, Cho Y, McCouch S (1997) Development of a microsatellite framework map providing genome-wide coverage in rice (Oryza sativa L.). Theor Appl Genet 95:553-567

Deng Y, Zhai K, Xie Z, Yang D, Zhu X, Liu J, Wang X, Qin P, Yang Y, Zhang G, Li Q, Zhang J, Wu S, Milazzo J, Mao B, Wang E, Xie H, Tharreau D, He Z (2017) Epigenetic regulation of antagonistic receptors confers rice blast resistance with yield balance. Science 355:1-4

Deng Y, Zhu X, Shen Y, He Z (2006) Genetic characterization and fine mapping of the blast resistance locus Pigm(t) tightly linked to Pi2 and Pi9 in a broadspectrum resistant Chinese variety. Theor Appl Genet 113:705-713

Divya B, Biswas A, Robin S, Rabindran R, Joel AJ (2014) Gene interactions and genetics of blast resistance and yield attributes in rice (Oryza sativa L.). J Genet 93:415-424

Ellur RK, Khanna A, Yadav A, Pathania S, Rajashekara H, Singh VK, Gopala Krishnan S, Bhowmick PK, Nagarajan M, Vinod KK, Prakash G, Mondal KK, Singh NK, Vinod Prabhu K, Singh AK (2016) Improvement of basmati rice varieties for resistance to blast and bacterial blight diseases using marker assisted backcross breeding. Plant Sci 242:330-341

Feechan A, Kocsis M, Riaz S, Zhang W, Gadoury DM, Walker MA, Dry IB, Reisch B, Cadle-Davidson L (2015) Strategies for RUN1 deployment using RUN2 and REN2 to manage grapevine powdery mildew informed by studies of race specificity. Phytopathology 105:1104-1113

Fjellstrom R, McClung AM, Conaway-Bormans CA, Park WD, Shank AR, Marchetti MA (2004) Development of DNA markers suitable for marker assisted selection of three genes conferring resistance to multiple pathotypes. Crop Sci 44:1790-1798

Gouda PK, Saikumar S, Varma CM, Nagesh K, Thippeswamy S, Shenoy V, Ramesha MS, Shashidhar HE (2013) Marker assisted breeding of Pi 1 and Piz 5 genes imparting resistance to rice blast in PRR78, restorer line of Pusa RH 10 basmati rice hybrid. Plant Breed 132:61-69

Hayashi K, Hashimoto N, Daigen M, Ashikawa I (2004) Development of PCR-based SNP markers for rice blast resistance genes at the Piz locus. Theor Appl Genet 108:1212-1220

Hittalmani S, Parco A, Mew T, Zeigler R, Huang N (2000) Fine mapping and DNA marker-assisted pyramiding of the three major genes for blast resistance in rice. Theor Appl Genet 100:1121-1128

IRRI (2002) Standard Evaluation System for Rice (SES). Los Banos, Philippines: IRRI, 2002: 15-16.

Jeung JU, Kim BR, Cho YC, Han SS, Moon HP, Lee YT, Jena KK (2007) A novel gene, Pi4O(t), linked to the DNA markers derived from NBS-LRR motifs confers broad spectrum of blast resistance in rice. Theor Appl Genet 115:1163-1177

Jia Y, McAdams SA, Bryan GT, Hershey HP, Valent B (2000) Direct interaction of resistance gene and avirulence gene products confers rice blast resistance. EMBO J 19:4004-4014

Jiang H, Feng Y, Bao L, Li X, Gao G, Zhang Q, Xiao J, Xu C, He Y (2012) Improving blast resistance of Jin $23 \mathrm{~B}$ and its hybrid rice by marker-assisted gene pyramiding. Mol Breed 30:1679-1688

Jiang J, Mou T, Yu H, Zhou F (2015) Molecular breeding of thermo-sensitive genic male sterile (TGMS) lines of rice for blast resistance using Pi2 gene. Rice ( $N$ Y) 8:11

Kawahara Y, de la Bastide M, Hamilton JP, Kanamori H, McCombie WR, Ouyang S, Schwartz DC, Tanaka T, Wu J, Zhou S, Childs KL, Davidson RM, Lin H, Quesada-Ocampo L, Vaillancourt B, Sakai H, Lee SS, Kim J, Numa H, Itoh T, Buell CR, Matsumoto T (2013) Improvement of the Oryza sativa Nipponbare reference genome using next generation sequence and optical map data. Rice (N Y) 6:4

Khan GH, Shikari AB, Vaishnavi R, Najeeb S, Padder BA, Bhat ZA, Parray GA, Bhat MA, Kumar R, Singh NK (2018) Marker-assisted introgression of three dominant blast resistance genes into an aromatic rice cultivar Mushk Budji. Sci Rep 8:4091

Khush GS, Jena KK (2009) Current status and future prospects for research on blast resistance in rice (Oryza sativa L.). Adv Genet Genomics Control Rice Blast Dis :1-10 https://link.springer.com/chapter/10.1007/978-1-4020-9500-9_1
Kiyosawa S (1967) The interitance of resistance of the zenith type varieties of rice to the blast fungus. Jap J Breed 17:99-107

Lai J, Li R, Xu X, Jin W, Xu M, Zhao H, Xiang Z, Song W, Ying K, Zhang M, Jiao Y, Ni P, Zhang J, Li D, Guo X, Ye K, Jian M, Wang B, Zheng H, Liang H, Zhang X, Wang S, Chen S, Li J, Fu Y, Springer NM, Yang H, Wang J, Dai J, Schnable PS (2010) Genome-wide patterns of genetic variation among elite maize inbred lines. Nat Genet 42:1027-1030

Li H, Durbin R (2009) Fast and accurate short read alignment with burrowswheeler transform. Bioinformatics 25:1754-1760

Liu G, Lu G, Zeng L, Wang GL (2002) Two broad-spectrum blast resistance genes, Pi9(t) and Pi2(t), are physically linked on rice chromosome 6. Mol Gen Genomics 267:472-480

Lu YJ, Zheng KL (1992) A simple method for extracting rice DNA. Chin J Rice Sci 6(1):47-48

Luo W, Huang M, Guo T, Xiao W, Wang J, Yang G, Liu Y, Wang H, Chen Z, Zhuang C (2017) Marker assisted selection for rice blast resistance genes Pi2 and Pi9 through high resolution melting of a gene targeted amplicon. Plant Breed 136:67-73

Mackill D, Bonman J (1992) Inheritance of blast resistance in near-isogenic lines of rice. Phytopathology 82:746-749

McClung A, Marchetti M, Webb B, Bollich C (1997) Registration of'Jefferson'rice. Crop Sci 37:629-630

McKenna A, Hanna M, Banks E, Sivachenko A, Cibulskis K, Kernytsky A, Garimella K, Altshuler D, Gabriel S, Daly M, DePristo MA (2010) The genome analysis toolkit: a MapReduce framework for analyzing next-generation DNA sequencing data. Genome Res 20:1297-1303

Pilet-Nayel ML, Moury B, Caffier V, Montarry J, Kerlan MC, Fournet S, Durel CE, Delourme R (2017) Quantitative resistance to plant pathogens in pyramiding strategies for durable crop protection. Front Plant Sci 8:1838

Poland JA, Brown PJ, Sorrells ME, Jannink JL (2012) Development of high-density genetic maps for barley and wheat using a novel two-enzyme genotypingby-sequencing approach. PLoS One 7:e32253

Puri KD, Shrestha SM, Chhetri GBK, Joshi KD (2009) Leaf and neck blast resistance reaction in tropical rice lines under green house condition. Euphytica 165 : $523-532$

Qu S, Liu G, Zhou B, Bellizzi M, Zeng L, Dai L, Han B, Wang GL (2006) The broadspectrum blast resistance gene Pi9 encodes a nucleotide-binding siteleucine-rich repeat protein and is a member of a multigene family in rice. Genetics 172:1901-1914

RoyChowdhury M, Jia Y, Jackson A, Jia MH, Fjellstrom R, Cartwright RD (2012) Analysis of rice blast resistance gene Pi-z in rice germplasm using pathogenicity assays and DNA markers. Euphytica 184:35-46

Scheuermann KK, Raimondi JV, Marschalek R, de Andrade A, Wickert E (2012) Magnaporthe oryzae genetic diversity and its outcomes on the search for durable resistance. In: The molecular basis of plant genetic diversity. Brazil: InTech http://intranetdoc.epagri.sc.gov.br/produca_tecnico_cientifica/DOC 19097.pdf

Sharma TR, Madhav MS, Singh BK, Shanker P, Jana TK, Dalal V, Pandit A, Singh A, Gaikwad K, Upreti HC, Singh NK (2005) High-resolution mapping, cloning and molecular characterization of the Pi-k (h) gene of rice, which confers resistance to Magnaporthe grisea. Mol Gen Genomics 274:569-578

Sharma TR, Rai AK, Gupta SK, Singh NK (2010) Broad-spectrum blast resistance gene $P i-k^{h}$ cloned from rice line Tetep designated as Pi54. J Plant Biochem Biotech 19:87-89

Skamnioti P, Gurr SJ (2009) Against the grain: safeguarding rice from rice blast disease. Trends Biotechnol 27:141-150

Tanweer FA, Rafii MY, Sijam K, Rahim HA, Ahmed F, Latif MA (2015) Current advance methods for the identification of blast resistance genes in rice. C R Biol 338:321-334

Variar M, Vera CCM, Carrillo MG, Bhatt JC, Sangar RBS (2009) Rice blast in India and strategies to develop durably resistant cultivars. In: Xiaofan W, Valent B (eds) Advances in genetics, genomics and control of rice blast disease. Springer, New York, pp 359-374

Wu Y, Chen Y, Pan C, Xiao N, Li Y, Zhang X, Pan X, Chen X, Liang C, Dai Z, Li A (2017) Development and evaluation of near-isogenic lines with different blast resistance alleles at the Piz locus in japonica rice from the lower region of the Yangtze River, China. Plant Dis 101:1283-1291

Wu Y, Yu L, Pan C, Dai Z, Li Y, Xiao N, Zhang X, Ji H, Huang N, Zhao B (2016) Development of near-isogenic lines with different alleles of Piz locus and analysis of their breeding effect under Yangdao 6 background. Mol Breed 36:1-12 
Xiao N, Wu Y, Pan C, Yu L, Chen Y, Liu G, Li Y, Zhang X, Wang Z, Dai Z, Liang C, Li A (2017) Improving of rice blast resistances in japonica by pyramiding major R genes. Front Plant Sci 7:1918

Xu C, Ladouceur M, Dastani Z, Richards JB, Ciampi A, Greenwood CM (2012)

Multiple regression methods show great potential for rare variant association tests. PLoS One 7:e41694

Yu J, Hu S, Wang J, Wong GK, Li S, Liu B, Deng Y, Dai L, Zhou Y, Zhang X, Cao M, Liu J, Sun J, Tang J, Chen Y, Huang X, Lin W, Ye C, Tong W, Cong L, Geng J, Han Y, Li L, Li W, Hu G, Li J, Liu Z, Qi Q, Li T, Wang X, Lu H, Wu T, Zhu M, Ni P, Han H, Dong W, Ren X, Feng X, Cui P, Li X, Wang H, Xu X, Zhai W, Xu Z, Zhang J, He S, Xu J, Zhang K, Zheng X, Dong J, Zeng W, Tao L, Ye J, Tan J, Chen X, He J, Liu D, Tian W, Tian C, Xia H, Bao Q, Li G, Gao H, Cao T, Zhao W, Li P, Chen W, Zhang Y, Hu J, Liu S, Yang J, Zhang G, Xiong Y, Li Z, Mao L, Zhou C, Zhu Z, Chen R, Hao B, Zheng W, Chen S, Guo W, Tao M, Zhu L, Yuan L, Yang H (2002) A draft sequence of the rice genome (Onzza sativa L. ssp. indica). Science 296:79-92

Yu Z, Mackill D, Bonman J, Tanksley S (1991) Tagging genes for blast resistance in rice via linkage to RFLP markers. Theor Appl Genet 81:471-476

Zhou B, Qu S, Liu G, Dolan M, Sakai H, Lu G, Bellizzi M, Wang GL (2006) The eight amino-acid differences within three leucine-rich repeats between Pi2 and Piz$t$ resistance proteins determine the resistance specificity to Magnaporthe grisea. Mol Plant-Microbe Interact 19:1216-1228

\section{Submit your manuscript to a SpringerOpen ${ }^{\circ}$ journal and benefit from:}

- Convenient online submission

- Rigorous peer review

- Open access: articles freely available online

- High visibility within the field

- Retaining the copyright to your article

Submit your next manuscript at $\boldsymbol{\nabla}$ springeropen.com 